\title{
MODIFICAÇÕES NOS ATRIBUTOS FÍSICOS DE SOLOS SUBMETIDOS A DOIS SISTEMAS DE PREPARO EM REBROTA DE Eucalyptus saligna ${ }^{1}$
}

\author{
Sandra Regina Cavichiolo ${ }^{2}$, Renato Antônio Dedecek ${ }^{3}$ e José Luiz Gava ${ }^{4}$
}

\begin{abstract}
RESUMO - Este trabalho teve como objetivos avaliar o efeito do revolvimento do solo das entrelinhas na produtividade de rebrota de Eucalyptus saligna, por meio das modificações em alguns atributos físicos do solo, e estabelecer qual profundidade de revolvimento apresenta maior ganho em produtividade em solos de texturas distintas, no Estado de São Paulo. Os sistemas de preparo foram: grade até $20 \mathrm{~cm}$ de profundidade e subsolador até $30 \mathrm{~cm}$. Foram obtidas amostras indeformadas do solo nas seguintes profundidades: 0 a 10,10 a 20 e 20 a $30 \mathrm{~cm}$, em nove repetições por tratamento; nos mesmos pontos foram coletadas amostras de solo para análise da fertilidade. Os seguintes atributos físicos do solo foram determinados: densidade do solo, porosidade total e de aeração, macro e microporosidade e da planta: altura e DAP (Diâmetro à Altura do Peito). No solo de textura média não houve efeito do preparo do solo no crescimento das plantas, sendo estabelecido correlação negativa entre a porosidade de aeração, na profundidade de 10 - $20 \mathrm{~cm}$, e o incremento em DAP $\left(r^{2}=0,74\right)$. Essa mesma correlação foi positiva no solo de textura argilosa $\left(r^{2}=0,78\right)$. No solo de textura argilosa, os dois sistemas de preparo de solo apresentaram maiores incrementos em altura e DAP do que a testemunha, diferindo estatisticamente no nível de $1 \%$, pelo teste de Tukey.
\end{abstract}

Palavras-chave: Densidade, porosidade de aeração, rebrota, Eucaliptus saligna e sistemas de preparo.

\section{MONITORING SOIL PHYSICAL CHARACTERISTICS IN Eucalyptus saligna COPPICE UNDER DIFFERENT SOIL TILLAGE SYSTEMS}

\begin{abstract}
The objective of this work was to evaluate soil physical characteristic changes in soil of different textures after mechanized harvesting under different tillage systems, in an area of Eucalyptus saligna coppice. The soils were a coarse Yellow Latosol and a Clayey Red Latosol occurring in an area of commercial plantation, in São Paulo State. Soil tillage systems were harrowing to 20-cm depth and subsoiling to a 30-cm depth. The following soil physical characteristics determined were bulk density, total and aeration porosity; and in the plant total height and DBH. There was no tillage effect on plants growing in the coarse soil, and there was a negative correlation between plant DBH and aeration porosity $\left(r^{2}=0.74\right)$. The same correlation was positive $\left(r^{2}=0,78\right)$ in the clayey soil. In the clayey soil, both soil tillage systems increased plant development in height and $D B H$, which were significantly different from the test plot without tilling the soil.
\end{abstract}

Keywords: Soil bulk density, soil aeration porosity and harrowing, subsoiling.

\footnotetext{
${ }^{1}$ Recebido em 19.03.2003 e aceito para publicação em 20.04.2005.

${ }^{2}$ Doutoranda em Engenharia Florestal, Setor de Ciências Agrárias, Departamento de Engenharia Florestal da UFPR 80210-170 Curitiba-Pr.

${ }^{3}$ Embrapa Florestas, C. Postal 319, 83411-000 Colombo-PR.

${ }^{4}$ Cia Suzano de Papel e Celulose, 18200-000 Itapetininga-SP.
} 


\section{INTRODUÇÃO}

A colheita mecanizada de florestas envolvendo o tráfego de veículos pesados durante o corte e transporte da madeira, passagens de máquinas e implementos para a aplicação de herbicidas, adubação e distribuição de resíduos no plantio e na rebrota pode resultar na compactação dos solos florestais. Tais operações comprometem importantes propriedades físicas desses solos, tendo como conseqüências a redução da capacidade produtiva dos sítios florestais e a erosão devido ao maior escorrimento superficial, que gera perdas de solo e nutrientes e, ainda, poluição dos cursos d' água por sedimentos. Dessa forma, a adoção de técnicas de preparo do solo após a colheita de madeira visa restaurar suas características físico-hídricas, garantindo o pleno desenvolvimento da segunda rotação, o que permite melhor crescimento das raízes, incorporação de restos da colheita (galhos, cascas, pedaços de madeira) e adubo, assegurando, assim, a sustentabilidade da produção florestal.

Os efeitos da compactação do solo sobre o crescimento das espécies florestais podem ser reduzidos pelo arado e pelo "riper", com a incorporação da serapilheira e resíduos no solo e aplicação de fertilizantes, mas a escolha das medidas de recuperação a serem aplicadas depende da intensidade da compactação, da classe de solo e da espécie florestal (WRONSKI e MURPHY, 1994). Ainda, o preparo envolve operações que devem ser realizadas em condições adequadas de umidade do solo, evitando, desse modo, agravar problemas de compactação abaixo do raio de ação dos implementos utilizados (OLIVEIRA, 1998).

A restauração da densidade do solo entre 0 - 15 $\mathrm{cm}$ de profundidade, em florestas submetidas à colheita mecanizada, foi observada por Gent et al. (1984), que obtiveram valores de densidade iguais ou abaixo dos observados antes da colheita, com o uso da grade de discos. Cintra (1996), analisando o desenvolvimento de coqueiro-gigante (Cocos nucifera L.) com a adoção de gradagem, constatou maior concentração de radicelas responsáveis pela maior parte da absorção de água e nutrientes na profundidade entre 0 e $20 \mathrm{~cm}$. Contudo, o uso da gradagem pode ser limitado pela presença de pedras ou quando o adensamento do solo atinge profundidades maiores que $20 \mathrm{~cm}$. Normalmente, o uso desse implemento em florestas é um preparo secundário, usado após o subsolador (RAB, 1998).
O riper e o subsolador estão entre os métodos mais populares para o estabelecimento e regeneração de sítios florestais, pois são operações que melhoram a sobrevivência e o crescimento das mudas, com a ressalva de que estas apresentam um sistema radicular mais estável, atingindo profundidades maiores. Também, expõem menor área de solo e não promovem o seu revolvimento, reduzindo o risco de erosão nos plantios florestais, entre as fases de plantio e cobertura do solo. A subsolagem empregada em plantio de Pinus echinata Mill mostrou-se benéfica, promovendo maior crescimento em altura, aumento no diâmetro de colo da raiz e volume das árvores (BERRY, 1979), e esse mesmo preparo promoveu o estabelecimento de mudas de Pinus elliotti mais rápido nos períodos de seca, provavelmente em função da maior facilidade de captação de água (STUART e NORRIS, 1995).

Este trabalho teve como objetivos avaliar o efeito do revolvimento do solo das entrelinhas na produtividade de rebrota de Eucalyptus saligna, através das modificações em alguns atributos físicos do solo (densidade, porosidade total e de aeração, macro e microporosidade do solo) e estabelecer qual profundidade de revolvimento apresenta maior ganho em produtividade em solos de texturas distintas.

\section{MATERIAL E MÉTODOS}

O presente estudo foi conduzido em área de rebrota de Eucalyptus saligna, exploração comercial de propriedade da Cia. Suzano de Papel e Celulose, no Estado de São Paulo. Foram selecionados dois talhões em localidades diferentes, com solos de texturas distintas: município de São Miguel Arcanjo, SP, em solo classificado como Latossolo Vermelho, textura argilosa; e município de Itatinga, SP, Latossolo Amarelo, textura média. Os dois talhões constituídos de florestas de eucalipto em $2^{a}$ rotação, com rebrota de dois anos na área de Latossolo Amarelo de textura média, e um ano na de Latossolo Vermelho de textura argilosa, na época da instalação do experimento. O espaçamento adotado foi de $3,0 \times 1,80$ e $3,0 \times 2,0 \mathrm{~m}$, respectivamente.

Na colheita realizada no solo de textura argilosa, foi empregado um harvester e no baldeio, utilizado um conjunto autocarregável, composto de trator agrícola Massey- Ferguson 610, com carreta e guincho hidráulico. No solo de textura média, a colheita foi realizada com motosserras e o baldeio, com autocarregável, formado 
por trator agrícola Valmet 1280 e uma carreta de um eixo com dois pneus (de caminhões) de cada lado. Os resíduos da colheita, como galhos, cascas e ponteiras, não foram removidos, permanecendo espalhados no local do corte.

O experimento foi conduzido em faixas por sistema de preparo do solo, num conjunto de cinco linhas em cada faixa, com quatro repetições e 125 plantas por parcela. A entrelinha onde permaneceu a galhada não sofreu tráfego das máquinas, e na colheita mecanizada se repetiu numa floresta de eucalipto a cada cinco linhas, constituindo estas a faixa de teste de cada sistema de preparo.

Foram testados os seguintes tratamentos: gradagem na entrelinha a uma profundidade de 10 a $20 \mathrm{~cm}$, sulcagem na entrelinha (subsolador monohaste) em profundidade de $30 \mathrm{~cm}$ e a testemunha sem preparo do solo. Nas duas áreas estudadas foram feitas avaliações dendrométricas de altura e DAP (Diâmetro a Altura do Peito) de todas as árvores do experimento, antes do revolvimento do solo (1997) e depois (1998), nas quatro parcelas de cada tratamento.

As amostragens do solo foram feitas depois do revolvimento, efetuadas nas três linhas onde havia maior probabilidade de compactação: linha de corte, empilhamento da madeira e baldeio em cada tratamento. Foram coletadas amostras indeformadas de solo, por meio de anéis volumétricos, nas três linhas selecionadas em cada tratamento, a $50 \mathrm{~cm}$ de distância da linha de plantio e em três profundidades: 0 - 10, 10 - 20, 20 $30 \mathrm{~cm}$, onde se determinaram: macro e microporosidade, porosidade total e de aeração, densidade do solo e curva de retenção de umidade $(6,10,100,500,1.500$ $\mathrm{kPa})$. Nos mesmos pontos foram coletadas amostras de solo para análises de fertilidade (Quadro 1).

A porosidade de aeração foi determinada a partir dos dados de umidade volumétrica do solo na capacidade de campo $(10 \mathrm{kPa})$, assumindo-se que esta corresponde ao teor de umidade retido no solo depois que o excesso de água gravitacional tenha sido drenado e o movimento descendente de água tenha decrescido significativamente (MONIZ, 1972). Os atributos físicos do solo, bem como as análises de fertilidade, foram determinados de acordo com a metodologia da Embrapa (1997).

\section{RESULTADOS E DISCUSSÃO}

\subsection{Análise dos atributos físicos do solo}

No Quadro 2, observa-se que os valores de densidade do solo de textura argilosa são bem menores que os resultados obtidos no solo de textura média, devido à textura do solo. Embora essa variável tenha sido afetada pelo tráfego e pelas operações de preparo, ela não apresentou valores críticos que pudessem comprovar compactação severa em nenhum dos dois solos.

Quadro 1 - Resultados da análise de fertilidade dos solos Table 1 - Results of soil fertility analyses

\begin{tabular}{|c|c|c|c|c|c|c|c|c|c|c|}
\hline \multirow[t]{2}{*}{ Textura } & \multirow{2}{*}{$\begin{array}{l}\text { Tratam. } \\
\text { Prof.(cm) }\end{array}$} & \multicolumn{3}{|c|}{$\operatorname{Corg}\left(\mathrm{g} / \mathrm{dm}^{3}\right)$} & \multicolumn{3}{|c|}{$\mathrm{pH}\left(\mathrm{CaCl}_{2}\right)$} & \multicolumn{3}{|c|}{$\mathrm{Ca}+\mathrm{Mg}\left(\mathrm{c} \cdot \mathrm{mol}_{\mathrm{c}} / \mathrm{dm}^{3}\right)$} \\
\hline & & 0 a 10 & 10 a 20 & 20 a 30 & 0 a 10 & 10 a 20 & 20 a 30 & 0 a 10 & 10 a 20 & 20 a 30 \\
\hline \multirow[t]{3}{*}{ Argilosa } & Test. & $4,01 \mathrm{a} *$ & $4,21 \mathrm{a}$ & $6,51 \mathrm{a}$ & $4,49 \mathrm{a}$ & $4,24 \mathrm{a}$ & $4,16 \mathrm{a}$ & $7,7 \mathrm{a}$ & $3,6 \mathrm{a}$ & $2,4 \mathrm{a}$ \\
\hline & Grade & $5,97 \mathrm{a}$ & $3,39 \mathrm{a}$ & $5,42 \mathrm{a}$ & $4,47 \mathrm{a}$ & $4,16 \mathrm{a}$ & $4,09 \mathrm{a}$ & $8,8 \mathrm{a}$ & $2,8 \mathrm{a}$ & $2,4 \mathrm{a}$ \\
\hline & Sulco & $6,49 a$ & $4,53 \mathrm{a}$ & $6,02 \mathrm{a}$ & $4,54 \mathrm{a}$ & $4,18 \mathrm{a}$ & $4,09 \mathrm{a}$ & $7,3 \mathrm{a}$ & $3,5 \mathrm{a}$ & $2,5 \mathrm{a}$ \\
\hline \multirow[t]{5}{*}{ Média } & Test. & $18,2 \mathrm{a}$ & $4,4 \mathrm{a}$ & $3,0 \mathrm{a}$ & $4,18 \mathrm{a}$ & $4,27 \mathrm{a}$ & $4,29 \mathrm{a}$ & $1,34 \mathrm{a}$ & $0,98 \mathrm{a}$ & $1,02 \mathrm{a}$ \\
\hline & Grade & $15,9 \mathrm{a}$ & $5,0 \mathrm{a}$ & $3,1 \mathrm{a}$ & $4,18 \mathrm{a}$ & $4,28 \mathrm{a}$ & $4,29 \mathrm{a}$ & $1,30 \mathrm{ab}$ & $0,99 a$ & $0,96 \mathrm{a}$ \\
\hline & Sulco & $15,5 \mathrm{a}$ & $4,6 \mathrm{a}$ & $2,5 \mathrm{a}$ & $4,14 \mathrm{a}$ & $4,31 \mathrm{a}$ & $4,29 \mathrm{a}$ & $0,97 b$ & $0,91 \mathrm{a}$ & $0,79 \mathrm{a}$ \\
\hline & & \multicolumn{3}{|c|}{$\mathrm{K}\left(\mathrm{c} . \mathrm{molc} / \mathrm{dm}^{3}\right)$} & \multicolumn{3}{|c|}{$\mathrm{P}\left(\mathrm{mg} / \mathrm{dm}^{3}\right)$} & \multicolumn{3}{|c|}{$\mathrm{H}+\mathrm{Al}\left(\mathrm{c} . \mathrm{molc} / \mathrm{dm}^{3}\right)$} \\
\hline & & 0 a 10 & 10 a 20 & 20 a 30 & 0 a 10 & 10 a 20 & 20 a 30 & 0 a 10 & 10 a 20 & 20 a 30 \\
\hline \multirow[t]{3}{*}{ Argilosa } & Test. & $0,30 \mathrm{a}$ & $0,10 b$ & $0,04 b$ & $3,6 \mathrm{a}$ & $2,2 \mathrm{a}$ & $1,0 \mathrm{a}$ & $12,6 \mathrm{a}$ & $11,9 \mathrm{a}$ & $11,7 \mathrm{a}$ \\
\hline & Grade & $0,41 \mathrm{a}$ & $0,20 \mathrm{a}$ & $0,10 \mathrm{a}$ & $2,8 \mathrm{a}$ & $2,6 \mathrm{a}$ & $1,3 \mathrm{a}$ & $13,0 \mathrm{a}$ & $13,0 \mathrm{a}$ & $12,3 \mathrm{a}$ \\
\hline & Sulco & $0,34 \mathrm{a}$ & $0,10 \mathrm{~b}$ & $0,05 b$ & $3,3 \mathrm{a}$ & $2,0 \mathrm{a}$ & $1,0 \mathrm{a}$ & $12,1 \mathrm{a}$ & $12,6 \mathrm{a}$ & $12,1 \mathrm{a}$ \\
\hline \multirow[t]{3}{*}{ Média } & Test. & $0,038 \mathrm{a}$ & $0,02 \mathrm{a}$ & $0,013 \mathrm{a}$ & $3,9 \mathrm{a}$ & $3,6 \mathrm{a}$ & $1,4 \mathrm{a}$ & $5,0 \mathrm{a}$ & $4,2 \mathrm{a}$ & $3,8 \mathrm{a}$ \\
\hline & Grade & $0,031 b$ & $0,02 \mathrm{a}$ & $0,018 \mathrm{a}$ & $3,1 \mathrm{ab}$ & $1,8 \mathrm{a}$ & $1,3 \mathrm{a}$ & $4,9 \mathrm{a}$ & $3,8 \mathrm{a}$ & $3,6 \mathrm{a}$ \\
\hline & Sulco & $0,028 b$ & $0,021 \mathrm{a}$ & $0,021 \mathrm{a}$ & $2,0 \mathrm{~b}$ & $3,4 \mathrm{a}$ & $3,8 \mathrm{a}$ & $4,9 \mathrm{a}$ & $4,2 \mathrm{a}$ & $3,7 \mathrm{a}$ \\
\hline
\end{tabular}

* Tratamentos seguidos das mesmas letras na mesma coluna não diferem entre si, pelo teste de Tukey a $5 \%$. 
Quadro 2 - Valores médios de densidade do solo, porosidade total e de aeração, macro e microporosidade obtidos a 50 $\mathrm{cm}$ da linha de plantio, nas três profundidades de todos o tratamentos, nos dois solos de texturas distintas, 1998

Table 2 - Bulk density, total and aeration porosity, macro and microporosity values, obtained from $50 \mathrm{~cm}$ of Eucalyptus saligna rows for the three treatments, in two different soils, 1998

\begin{tabular}{|c|c|c|c|c|c|c|c|}
\hline & & & $\begin{array}{c}\text { Densidade } \\
\text { do Solo }\end{array}$ & $\begin{array}{c}\text { Porosidade } \\
\text { Total }\end{array}$ & $\begin{array}{l}\text { Porosidade } \\
\text { de Aeração }\end{array}$ & Macroporos & Microporos \\
\hline \multirow[t]{4}{*}{ Solo } & Trat. & Prof. $\mathrm{cm}$ & $\mathrm{Mg} / \mathrm{cm}^{3}$ & $\mathrm{~cm}^{3} / \mathrm{cm}^{3}$ & $\%$ & $\%$ & $\%$ \\
\hline & Teste & & $1,26 \mathrm{a}^{*}$ & $0,549 a$ & $32,28 \mathrm{a}$ & $26,67 \mathrm{a}$ & $28,00 \mathrm{a}$ \\
\hline & Gradagem & 0 a 10 & $1,32 \mathrm{a}$ & $0,526 a$ & $26,84 \mathrm{a}$ & $23,75 \mathrm{a}$ & $29,00 \mathrm{a}$ \\
\hline & Sulcagem & & $1,26 \mathrm{a}$ & $0,549 a$ & $29,92 \mathrm{a}$ & $26,27 \mathrm{a}$ & $29,00 \mathrm{a}$ \\
\hline Textura & Teste & & $1,47 \mathrm{a}$ & $0,455 \mathrm{a}$ & $20,66 a$ & $17,88 \mathrm{a}$ & $28,00 \mathrm{a}$ \\
\hline \multirow[t]{8}{*}{ Média } & Gradagem & 10 a 20 & $1,49 \mathrm{a}$ & $0,447 \mathrm{a}$ & $17,74 \mathrm{a}$ & $14,33 \mathrm{a}$ & $30,00 \mathrm{a}$ \\
\hline & Sulcagem & & $1,55 \mathrm{a}$ & $0,425 \mathrm{a}$ & $16,75 \mathrm{a}$ & $12,89 a$ & $30,00 \mathrm{a}$ \\
\hline & Teste & & $1,48 \mathrm{a}$ & $0,489 a$ & $26,57 \mathrm{a}$ & $21,98 \mathrm{a}$ & $27,00 \mathrm{a}$ \\
\hline & Gradagem & 20 a 30 & $1,48 \mathrm{a}$ & $0,489 a$ & $27,69 a$ & $22,52 \mathrm{a}$ & $26,00 a$ \\
\hline & Sulcagem & & $1,54 \mathrm{a}$ & $0,466 a$ & $25,68 \mathrm{a}$ & $18,29 a$ & $28,00 \mathrm{a}$ \\
\hline & Teste. & & $0,87 \mathrm{ab}$ & $66,15 \mathrm{ab}$ & $21,30 a$ & $18,31 \mathrm{a}$ & $48,00 \mathrm{a}$ \\
\hline & Gradagem & 0 a 10 & $0,79 \mathrm{~b}$ & $69,55 a$ & $27,88 \mathrm{a}$ & $24,75 a$ & $45,00 \mathrm{a}$ \\
\hline & Sulcagem & & $0,93 \mathrm{a}$ & $64,01 b$ & $18,73 \mathrm{a}$ & $16,13 \mathrm{a}$ & $48,00 \mathrm{a}$ \\
\hline Textura & Teste & & $1,04 \mathrm{a}$ & $62,03 a$ & $16,46 a$ & $12,78 \mathrm{a}$ & $50,00 a$ \\
\hline \multirow[t]{5}{*}{ Argilosa } & Gradagem & 10 a 20 & $0,98 \mathrm{a}$ & $63,68 \mathrm{a}$ & $18,49 a$ & $14,23 \mathrm{a}$ & $49,00 a$ \\
\hline & Sulcagem & & $1,01 \mathrm{a}$ & $63,83 \mathrm{a}$ & $19,75 \mathrm{a}$ & $15,35 \mathrm{a}$ & $50,00 a$ \\
\hline & Teste & & $0,95 \mathrm{a}$ & $64,66 a$ & $20,11 \mathrm{a}$ & $15,20 \mathrm{a}$ & $46,00 \mathrm{a}$ \\
\hline & Gradagem & 20 a 30 & $0,89 a$ & $67,09 a$ & $25,26 a$ & $20,81 \mathrm{a}$ & $49,00 a$ \\
\hline & Sulcagem & & $0,90 \mathrm{a}$ & $66,58 \mathrm{a}$ & $24,35 \mathrm{a}$ & $20,39 a$ & $46,00 \mathrm{a}$ \\
\hline
\end{tabular}

* Tratamentos seguidos pelas mesmas letras não diferem pelo teste de Tukey a 5\%.

No solo de textura argilosa, os tratamentos apresentaram diferenças significativas quando submetidos ao teste de Tukey $5 \%$, na profundidade de $0-10 \mathrm{~cm}$, onde a gradagem exibiu menor densidade. A testemunha manifestou os maiores valores de densidade nas outras duas camadas em relação aos dois tratamentos com revolvimento do solo. A sulcagem apresentou valores maiores que a gradagem, em razão do menor revolvimento do solo nessa operação. No solo de textura média não houve diferenças significativas entre os tratamentos, ressaltando-se que a testemunha manifestou os menores resultados de densidade do solo.

Entre as três profundidades avaliadas, a camada de $0-10 \mathrm{~cm}$ apresentou os menores valores de densidade em ambos os solos, mesmo na testemunha, em que não foi efetuado o preparo do solo. Tal fato pode ser atribuído à camada de resíduos de colheita presente no solo que reduzem o impacto causado pelas máquinas, diminuindo a compactação (SOANE, 1990). Os processos de secagem e umedecimento do solo ocorrem com maior freqüência na superfície, facilitando a recuperação da sua estrutura nessa camada. Também, a influência de matéria orgânica é sempre maior na superfície, considerando-se que o corte é efetuado depois do sétimo ano do plantio, acrescentando ao solo muito material orgânico e, dessa forma, favorecendo a recuperação de suas características físicas.

$\mathrm{Na}$ camada entre $10-20 \mathrm{~cm}$, os resultados de densidade do solo encontrados foram sempre os maiores, situação semelhante à relatada por Fernandes (1998), avaliando os efeitos da colheita florestal sobre um Latossolo Vermelho de textura argilosa. Esse autor observou que na camada entre $15-30 \mathrm{~cm}$ os resultados de densidade do solo oscilaram entre 0,97 e 1,09 Mg/ $\mathrm{cm}^{3}$, superiores aos encontrados na camada superficial. Devem-se considerar nessa profundidade os fatores que favorecem a recuperação da estrutura do solo, por exemplo os teores de água, que são alternados com menor freqüência nessa camada e, ainda, os conteúdos de matéria orgânica, menores que na camada superficial.

Os valores de porosidade total (Quadro 2), obtidos no solo argiloso, são maiores que os conseguidos no solo de textura média, em função do arranjamento das partículas de areia nesta última. No solo de textura 
média não foram encontradas diferenças significativas e os resultados concordam com os valores de densidade do solo nessa área. No solo argiloso, os valores de porosidade total obtidos nos diferentes tratamentos diferiram estatisticamente entre si apenas na profundidade de $0-10 \mathrm{~cm}$; a gradagem apresentou os menores valores, em concordância com os resultados de densidade do solo.

Os valores de macroporosidade do solo argiloso (Quadro 2) encontram-se, em média, em torno de $25 \%$ menores do que no de textura média, naturalmente em função da textura. Mesmo sem diferenciação estatística, percebe-se, nesse quadro, que a testemunha, sem preparo do solo, manifestou os menores resultados. Já na microporosidade (Quadro 2) as diferenças entre os três tratamentos nesse solo não foram tão acentuadas. No solo de textura média, até as profundidades avaliadas, as porcentagens de macro e microporos apresentamse quase que na mesma proporção em praticamente todos os tratamentos. Para permitir uma comparação dos resultados nos dois locais (Quadro 3), corrigiuse a porcentagem de macro e microporos para $100 \%$, sendo possível determinar quanto da porosidade total era composta pelos dois tamanhos de poros. Podese dizer que uma redução de até 50\% na macroporosidade deixaria o solo de textura média com uma porosidade semelhante ao de textura argilosa, fato esse que pode ser favorável, considerando-se a capacidade de retenção de água deficiente nesse tipo de solo.

Os resultados da porosidade de aeração não indicaram diferenças significativas em dois solos em estudo. No argiloso, nenhum dos tratamentos mostrou valores críticos, ou seja, inferiores a $10 \%$, porém algumas amostras dentro do tratamento da sulcagem e na testemunha apresentaram valores pouco abaixo desse, no entanto a porosidade total não foi afetada. Segundo Prevedello (1996), quando a intensidade de compactação não é muito grande, a quantidade de poros de tamanho intermediário pode ser aumentada e os poros internos dos agregados, permanecer inalterados. No solo de textura argilosa, observou-se o incremento em DAP em função do aumento da porosidade de aeração $\left(r^{2}=0,78\right)$.

No solo de textura média, obteve-se correlação negativa entre a porosidade de aeração do solo e o incremento em DAP $\left(r^{2}=0,74\right)$, ocorrendo os maiores incrementos em DAP para menores valores de porosidade de aeração, em virtude do aumento da microporosidade (Figura 1). No entanto, nesse mesmo solo a densidade (50 cm de distância da linha) na profundidade de 0 - $10 \mathrm{~cm}$ indicou que o aumento na densidade reduz o incremento em DAP $\left(\mathrm{r}^{2}=0,57\right)$.

\subsection{Dados de produtividade da rebrota de eucalipto nas duas áreas experimentais}

No solo argiloso, os resultados do incremento em DAP nos tratamentos de gradagem e sulcagem diferiram significativamente da testemunha no nível indicado, pelo teste de Tukey, como mostrado na Figura 2. Para a avaliação em altura não houve diferenças estatísticas, no entanto o tratamento da sulcagem manifestou os maiores valores médios, enquanto a testemunha (sem preparo do solo) apresentou os menores dados de incremento, justificando a necessidade de preparo do solo pelo aumento de produtividade da rebrota de eucalipto.

Quadro 3 - Porosidade total, macro e microporosidade corrigidas dos dois solos, nos três tratamentos, 1998 Table 3 - Total porosity, macro e microporosity corrected for the three treatments, in two different soils, 1998

\begin{tabular}{|c|c|c|c|c|c|c|c|c|c|c|}
\hline \multirow{3}{*}{ Solo } & \multirow{3}{*}{ Prof. $(\mathrm{cm})$} & \multicolumn{3}{|c|}{ Testemunha } & \multicolumn{3}{|c|}{ Grade } & \multicolumn{3}{|c|}{ Sulco } \\
\hline & & \multicolumn{3}{|c|}{ Porosidade rel.(\%) } & \multicolumn{3}{|c|}{ Porosidade rel.(\%) } & \multicolumn{3}{|c|}{ Porosidade rel.(\%) } \\
\hline & & Total & Macro & Micro & Total & Macro & Micro & Total & Macro & Micro \\
\hline \multirow{3}{*}{$\begin{array}{l}\text { Textura } \\
\text { argilosa }\end{array}$} & 0 a 10 & 66,3 & 27,6 & 72,4 & 69,7 & 35,4 & 64,6 & 64,1 & 25,1 & 74,9 \\
\hline & 10 a 20 & 62,8 & 20,4 & 79,6 & 63,2 & 22,5 & 77,5 & 65,3 & 23,4 & 76,6 \\
\hline & 20 a 30 & 61,2 & 24,8 & 75,2 & 69,9 & 29,8 & 70,1 & 66,4 & 30,7 & 69,3 \\
\hline \multirow{3}{*}{$\begin{array}{l}\text { Textura } \\
\text { média }\end{array}$} & 0 a 10 & 54,7 & 48,8 & 51,2 & 52,7 & 45,0 & 55,0 & 55,3 & 47,6 & 52,4 \\
\hline & 10 a 20 & 45,9 & 39,0 & 61,0 & 44,3 & 32,3 & 67,7 & 42,9 & 30,1 & 69,9 \\
\hline & 20 a 30 & 49,0 & 44,9 & 55,1 & 48,5 & 46,4 & 53,6 & 46,3 & 39,5 & 60,5 \\
\hline
\end{tabular}




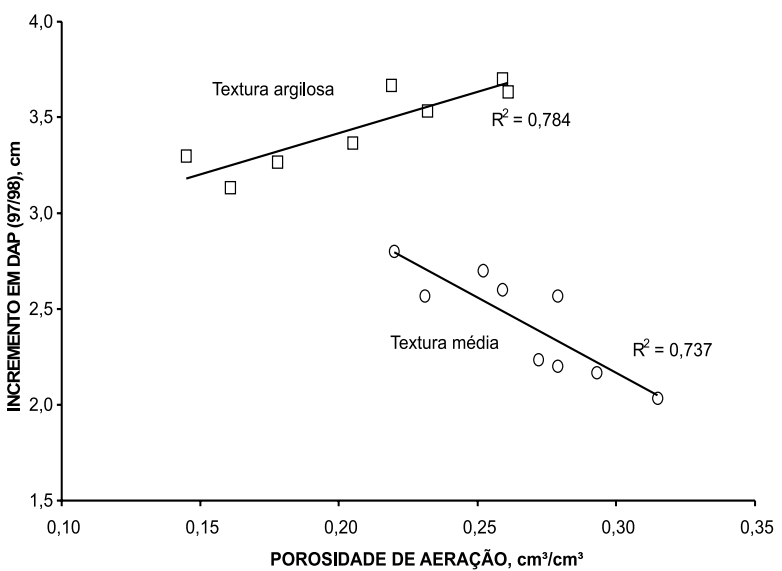

Figura 1 - Correlações entre porosidade de aeração $\left(\mathrm{cm}^{3} /\right.$ $\mathrm{cm}^{3}$ ) e incremento em DAP.

Figure 1 - Correlations between aeration porosity $\left(\mathrm{cm}^{3} / \mathrm{cm}^{3}\right)$ and $D B H$ increase.

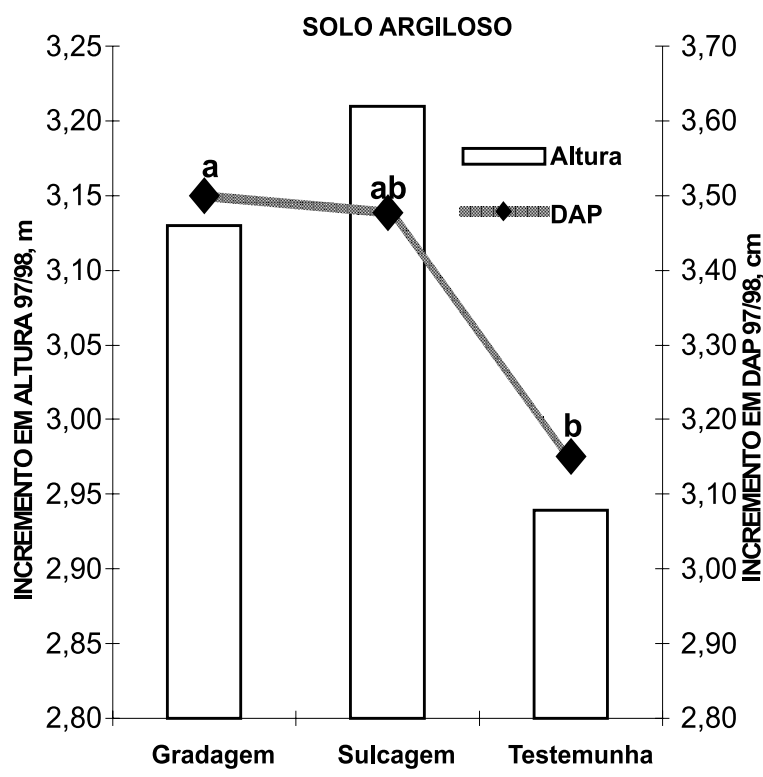

Figura 2 - Incremento em altura e DAP de rebrota de Eucalyptus saligna de acordo com os sistemas de preparo do solo argiloso, 1998. No incremento em DAP, letras distintas indicaram diferenças significantes entre as médias dos tratamentos pelo teste de Tukey a $1 \%$.

Figure 2 - Height and DBH increase in Eucalyptus saligna coppice according to tillage systems in clayey soil. In DBH increase, different letters showed significant differences between means of the treatments by the Tukey's test, $1 \%$ significance level.
No solo de textura média (Figura 3) não foram encontradas diferenças estatísticas para o incremento em altura e DAP, e a gradagem manifestou os menores valores de altura e DAP, indicando que o revolvimento superficial com a incorporação da serapilheira deve ser menos eficiente do que mantê-la na superficie, onde se reduzem as perdas de umidade. Nessa camada, a areia está quase sempre seca, afetando, assim, o transporte e absorção de nutrientes. A evaporação da água do solo também é favorecida pelo aumento da porosidade total, o que, conseqüentemente, acaba afetando o melhor aproveitamento do adubo, que normalmente ocorre em maior concentração na camada superficial.

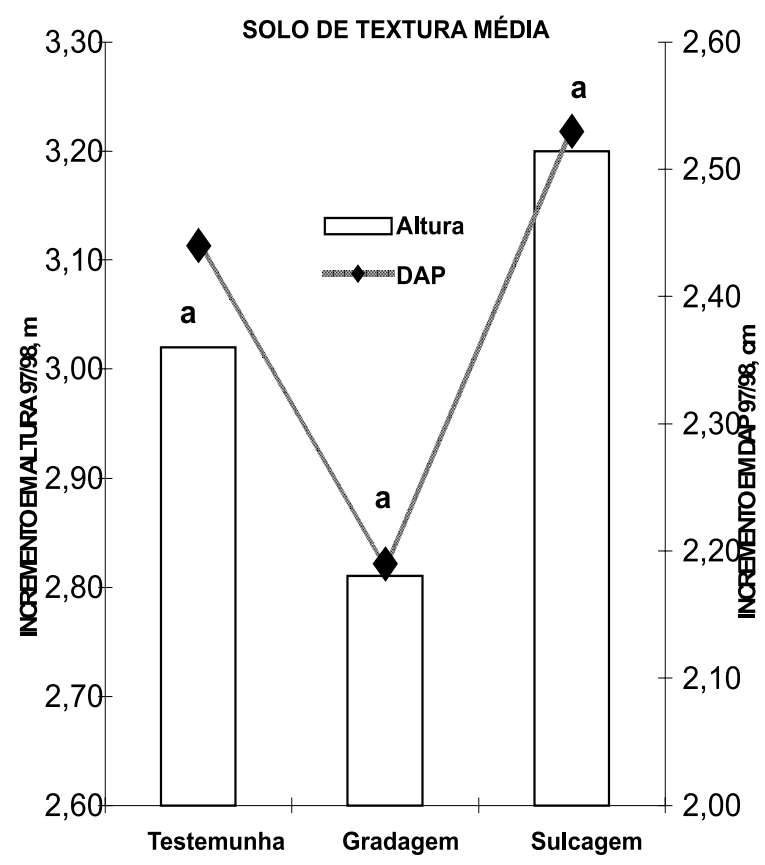

Figura 3 - Incremento em altura e DAP de Eucalyptus saligna de acordo com os sistemas de preparo do solo de textura média - 1998.

Figure 3 - Height and DBH increase in Eucalyptus saligna coppice according to tillage systems in coarse Yellow Latosol - 1998.

\section{CONCLUSÕES}

A compactação do solo em função das operações mecanizadas foi mais evidente na camada entre $10 \mathrm{e}$ $20 \mathrm{~cm}$ de ambos os solos estudados, em que no de textura média valores maiores de densidade do solo se mantiveram até os $30 \mathrm{~cm}$ de profundidade. 
Os efeitos do preparo do solo na condição de estudo foram mais evidentes no solo de textura argilosa do que no de textura média, na avaliação da produtividade de rebrota.

No solo de textura argilosa, o revolvimento resultou em maior desenvolvimento da rebrota de Eucalyptus saligna, do segundo para o terceiro ano após o corte raso, apresentando diferença estatística de incremento em DAP. Já no de textura média o revolvimento pela gradagem até os $20 \mathrm{~cm}$ de profundidade manifestou menor incremento em altura e DAP, do primeiro para o segundo ano. Para a sulcagem e a testemunha, os dados de crescimento obtidos não mostraram diferenças expressivas, não justificando a operação nesse solo.

Uma leve compactação no solo de textura média favoreceu um aumento na microporosidade na camada entre $10-20 \mathrm{~cm}$ de profundidade. A quantidade de microporos observada atingiu valores praticamente equivalentes aos do solo de textura argilosa, o que pode ter favorecido a maior retenção de água nesse tipo de solo.

Foi observada uma correlação linear positiva $\left(r^{2}=0,78\right)$ entre porosidade de aeração e incremento em DAP no solo argiloso, enquanto no solo arenoso essa correlação mostrou-se negativa $\left(r^{2}=0,74\right)$.

\section{REFERÊNCIAS BIBLIOGRÁFICAS}

BERRY, C. R. Subsoiling improves growth of pine on Georgia Piedmont site. Washington: USDA Forest Service Research. 1979. 3 p. (Note SE-284).

CINTRA, F. L.D.; FONTES, H. R.; LEAL, M. L. S. Distribuição do sistema radicular do coqueiro gigante do Brasil submetido a diferentes sistemas de manejo do solo. Revista Brasileira de Ciência do Solo, v. 20, p. 327-332, 1996.

\section{EMPRESA BRASILEIRA DE PESQUISA} AGROPECUÁRIA - EMBRAPA - Centro Nacional de Pesquisa de Solos. Manual de métodos de análise de solo. 2. ed. Rio de Janeiro: EMBRAPA-CNPS, 1997.212 p. (EMBRAPA-CNPS, 1).
FERNANDES, H. C.; VITORIA, E. L.; Avaliação dos níveis de compactação de um solo florestal em relação à trafegabilidade das máquinas.

Revista Árvore, v. 22, n. 4, p. 521-526, 1998.

GENT, J. A. et al. Impact of harvesting and site preparation on physical properties of Piedmont forest soils. Soil Science Society

American Journal, v. 48, p. 173-177, 1984.

MONIZ, A. C. Elementos de pedologia. São Paulo: Polígono, 1972. 459 p.

STUART, R.; NORRIS, C. H. Regenaration methods. Scottsville: Institute for Commercial Forestry Research. 1995. p. 35-69. (Annual Research Report).

OLIVEIRA, C. V.; BAHIA, V. G.; PAULA, M. B. Compactação do solo devido a mecanização florestal: causas, efeitos e práticas de controle. Informe Agropecuário, v. 19, n. 191, p. 4648, 1998.

PREVEDELLO, C. L.Física do solo com problemas resolvidos. Curitiba: SAEAFS, 1996. $446 \mathrm{p}$.

RAB, M. A. Rehabilitation of snig tracks and landings following of Eucalyptus regnans forest in the Victorian Central Highlands - a Review Australian Forestry, v. 61, n. 2, p. 103-113, 1998.

SOANE, B. D. The Role of organic matter in soil compactibility: a review of some practical aspects. Soil \& Tillage Research, v.16, n. 1-2, p. 179-201, 1990.

WRONSKI, E. B.; MURPHY, G. Responses of forest crops to soil compaction. Soil compaction in crop production. New York: Elsevier Science, 1994. p. 317-342. 